\title{
Private Supplementary Tutoring and Socio-economic Differences in Access to Higher Education
}

\section{Kosunen, Sonja}

$2021-12$

Kosunen , S , Haltia , N , Saari , J , Jokila , S \& Halmkrona, E 2021, ' Private

Supplementary Tutoring and Socio-economic Differences in Access to Higher Education ', Higher Education Policy , vol. 34 , no. 4 , pp. 949-968 . https://doi.org/10.1057/s41307-020-00177-y

http://hdl.handle.net/10138/339872

https://doi.org/10.1057/s41307-020-00177-y

acceptedVersion

Downloaded from Helda, University of Helsinki institutional repository.

This is an electronic reprint of the original article.

This reprint may differ from the original in pagination and typographic detail.

Please cite the original version. 


\title{
Private Supplementary Tutoring and Socio-economic Differences in Access to Higher Education
}

\author{
Sonja Kosunen, Nina Haltia, Juhani Saari, Suvi Jokila \& Esa Halmkrona \\ Higher Education Policy (2020). https://doi.org/10.1057/s41307-020-00177-y
}

\begin{abstract}
Private supplementary tutoring in the form of preparatory courses to university entrance examinations, is present in Finland alongside public higher education (HE). We explore the participation in preparatory courses. Our data derives from the university undergraduate subsample $(n=2,969)$ of a larger cross-sectional national survey targeting tertiary students. We found a strong association between the SES of the students and preparatory-course-participation rates. Preparatorycourse participation is also more common in competitive disciplines. Students from higher SES backgrounds get more parental help in financing their participation than their counterparts coming from lower SES backgrounds. Thereby the role of private economic capital in the access to HE in Finland, despite its tuition-fee-free nature, is evident.
\end{abstract}

Keywords: access, higher education, private supplementary tutoring, socio-economic status

\section{Introduction}

Choice in higher education (HE) has been a prominent research theme in the sociology of education for a while. Ball et al. (2002: 52-53) refer to two registers of meaning and action in HE choice: the matching of performance to the selectivity of institutions and disciplines, and the embedding of 'social classifications of self and institutions'. The HE admission-process is mediated through different systemic, institutional and social mechanisms, such as national and local-level regulations, admission policies and selection procedures, as well as institutional stratification in local contexts. All these comprise a space of educational choice (Kosunen, 2016), as well as a competition space (Taylor, 2002) in which prospective students of HE operate. The key questions in competitive HE systems based on entrance examinations, such as in Finland, concern who are admitted and by what means, how students are selected from the pool of applicants, and whether this process is equitable (see Pitman, 2016). From the perspective of social justice in education, therefore, it is highly relevant to investigate mediating mechanisms such as the role of private tutoring, and their influence on the selection and choice procedures followed by applicants from different social backgrounds. This at large deals with the variety of questions arising from privatisation in public education (see Ball \& Youdell, 2008; Lynch, 2006).

Research attention has recently been given to the process of accessing HE in different local contexts with different educational systems, admission policies and financial constraints. The specific foci include socio-economic and social-class differences in the choices made (Archer et al., 2003; Ball et al., 2002; Reay et al., 2001; Sianou-Kyrgiou \& Tsiplakides, 2011); meritocracy and 'fairness' (or sometimes equity) in student selection (Mountford-Zindars \& Sabbagh, 2013; Pitman, 2016; McCowan, 2016; Halsey, 1993; Williams, 1997) and the connection between academic success and social background (Declerq \& Verboven, 2015; Sianou-Kyrgiou \& Tsiplakides, 2011); patterns of reproduction (Naidoo, 2004; Thomsen, 2012; Bathmaker et al., 2013), policies of widening participation (Callender, 2006; Callender \& Jackson, 2005); and alternative processes of student selection used in elite institutions (van Zanten, 2010). The findings indicate that there is a connection between admission to $\mathrm{HE}$ and the social background of the prospective student, the influence of which spreads even further to labour-market participation (Marginson, 2016). 
This article draws its frame from international studies on socio-economic differences and private capital in accessing HE, but steps aside from widening participation studies, as there are no explicit widening participation policies in Finland due to tuition-fee-free education and reasonably equal structure of university admission policies. We contribute to the discussion on $\mathrm{HE}$ in Finland concerning socio-economic differences in admissions, and especially in attendance at preparatory courses for candidates taking the entrance examinations. We conceptualize this form of private education as private supplementary tutoring (see e.g. Hallsén \& Karlsson, 2018), which is also discussed synonymously as shadow education (e.g. Stevenson \& Baker, 1992; and Matsuoka 2018; Smyth, 2009) in the research literature, referring to private education, which functions alongside the public education system.

There are some reports and recent research papers (see e.g. Ahola et al., 2017; 2018; Kosunen et al., 2015; 2018; Kosunen \& Haltia, 2018; Kosunen, 2018) exploring the role of private supplementary tutoring involved in university admission in Finland. However, the mediating devices and mechanisms in the university admission producing socio-economically biased outcomes (see Nori, 2011; Kilpi-Jakonen et al. 2016) are an underexplored thematic area in Finland. The significance of this analysis lies in further exploring the fact that previous studies conducted in Finland show how urban applicants from higher socio-economic backgrounds are more likely to apply to and to be accepted at higher education institutes (Nori, 2011) even though, thus far, there are no tuition fees in the HE system. The role of economic capital as a mediator in this process has been under-explored, which is a gap in the research literature we hereby aim to narrow. This paper focuses on participation in preparatory courses, and addresses the question of how money becomes involved in the allocation of student places in HE in Finland. Our data derives from the university undergraduate subsample $(n=2,969)$ of a larger cross-sectional national survey targeting tertiary students.

\section{Socio-economic Differences in Access to Higher Education}

Pierre Bourdieu (1996) states in his classic book The State Nobility that higher education is a sorting machine selecting students according to an implicit social classification and reproducing those positions among the same students via an academic classification. His well-known theory of the transmission of cultural capital (Bourdieu, 1984) within families and as part of educational systems has inspired a wide range of research literature (e.g. Ball et al., 2002; Bathmaker et al., 2013). Access to HE functions as a starting point from which to explore the relationship between academic 'talent' and its linkage to the social properties of the individual candidate, in which the role of social origin in academic selection is often misrecognized or even denied (Naidoo, 2004). According to Ball et al. (2002), cultural, social and economic capital, distinctions and patterns of self-exclusion are all at play in the process of accessing HE. Investigating the interplay among these elements would therefore be beneficial in terms of explaining how and through what mediating mechanisms HE student populations remain socially unbalanced.

The process of admission is strongly connected to the idea of choice, which as such is a multifaceted concept. Two main traits are acknowledged: social and economic choice. In line with the work of Diane Reay (1998), the choice of HE is understood in this study as a complex process involving social aspects such as the family's prior experience of HE that are embedded in both the familial and the institutional habitus, as well as geographical constraints. The geography of HE clearly plays a major role in this process (see Mangan et al., 2010). There are known differences between working-class students and students from the middle and upper classes in terms of admission processes (Archer \& Hutchings, 2000; Reay, 2003; Reay et al., 2001). Working-class students with similar performance standards as their middle-class counterparts seem to make different HE choices, and to engage in the admission process with more uncertainty and insecurity (Sianou-Kyrgiou \& Tsiplakides, 2011). Young people from poorer backgrounds are also less likely to attend the most prestigious disciplines 
in universities (Crawford et al. 2016). The role of social background as part of the process in different contexts should therefore be acknowledged.

Another focus of study in the area of access to HE is the financial aspect and the influence of economic capital on the choice of higher education, the higher education institution (HEI) and the subject of study. Callender and Jackson (2008) demonstrated how an increase in tuition fees, for example, and other financial issues related to admission have a far larger effect on students with a lower SES than on those from higher social backgrounds in terms of the choice of university, but not on qualifications or the subject of study. Students from lower social backgrounds consider the economic burden of paying higher tuition fees a debt rather than an investment, which is how their middle-class counterparts see it (Callender \& Jackson, 2008; see also Harrison \& Hatt, 2012). The financial conditions of working-class students affect their choices, leading them to opt for local higher education institutions, for example, whereas their middle-class counterparts are more academicallyor status-oriented in their reasoning, and finance plays a minor role (see Sianou-Kyrgiou \& Tsiplakides, 2011, 90; Forsyth \& Furlong, 2000).

To complement research on overall participation in HE among students from different social backgrounds, Sianou-Kyrgiou \& Tsiplakides (2011) also call for more thorough investigation into institutional stratification and qualitative differentiation in HE institutions, and their connections to differentiation by social class. The expansion of the HE market as such does not help in terms of tackling the persisting inequalities in the admission process (Sianou-Kyrgiou \& Tsiplakides, 2011; McCowan, 2016): as the market expands, affluent families tend to dominate the elite institutions (Marginson, 2016). McCowan (2016) points out the range of political debate on this issue, exposing tensions between equity and efficiency, public and private spheres, academic and vocational orientations, and finally, perspectives on abilities and potential. Although most of these aspects are beyond the scope of this article, they provide relevant background information about this emerging phenomenon in each local context.

\section{Private Supplementary Tutoring Alongside the Official Systems}

Although social background and economic capital are embedded in the choice of HE, they may remain unarticulated in the context of a tuition-fee-free system. The term private supplementary tutoring (Pearce, Power \& Taylor, 2017) is usually applied in the case of comprehensive and secondary education, but we use it in this article with regard to gaining access to HE. The aim of this sort of unofficial, fee-based education outside the public forum is to enhance customers' access to their desired study places. Stevenson and Baker (1992) define shadow education as 'a set of educational activities outside formal schooling that are designed to improve a student's chances of successfully moving through the allocation process'. Shadow education flourishes specifically in national contexts in which formal examinations are used in the allocation process, and when there is intense competition for student places in universities, especially in the most prestigious institutions. It could even be seen in some national contexts as an institutionalized part of the 'formal educational allocation system' (Stevenson \& Baker, 1992).

Bray (2010) refers to the difficulty of investigating shadow education in local contexts, given its hidden and private nature. A crucial aspect is the paradoxical role of tuition fees, which function simultaneously as reinforcing and weakening forces in terms of the socio-economically based privileges in education (Pearce, Power \& Taylor, 2017). Shadow education is known to function as an asset, and even an additional asset for those who are already in a privileged position. Students purchasing private tutoring comprise a selected group already in possession of different types of relevant capital in this competitive situation. They have better grades, spend more time on homework, come from wealthier families and have parents with higher levels of education than those who do not 
participate in private tutoring (Smyth, 2009). However, shadow education has also been accessed by families from lower socio-economic backgrounds (Bray, 2011).

As Smyth (2009) states, private tutoring should not be seen as a rational strategy to secure success in the allocation process. Rather, it should be regarded as a reaction to the competitive context in which expectations from different sides, such as parents and teachers, create feelings of pressure to succeed in the allocation process.

\section{Private Supplementary Tutoring in the Finnish Educational Context}

The common discourse in Finland, as well as in Nordic-welfare-state models more generally, stresses that access to HE should not be dependent on family wealth or parental social status. To downplay the effect of financial assets, as a matter of principle tuition fees are not charged for degree-level education $^{1}$, and this is applied on an egalitarian basis to everyone, not just those who come from lowincome families or disadvantaged backgrounds (see Thomsen et al., 2013). Geographical availability is another principle that promotes equal opportunities in HE. The Finnish HE system was extended after the Second World War with the founding of several regional universities outside the capital area. Later, in the 1990s, polytechnic institutions were introduced operating alongside traditional universities, thereby extending the opportunities and opening a route to more vocationally oriented studies within HE. (Jalava 2013) Currently, the HE system is a dual model comprising traditional universities and universities of applied sciences (UAS) (Ministry of Education and Culture, 2016) ${ }^{2}$. Complementing these institutions, some private universities governed from abroad entered the Finnish HE market during the 2010s, mainly focused on business and economics, but they play a marginal role.

Gaining access to HE is very competitive in Finland. Most universities have thus far practised selection based on grades in the matriculation examination, which is a national test taken at the end of upper-secondary school, and entrance examinations that test knowledge based on external material selected by the university. The competitive process of accessing universities, especially in high-status disciplines such as law and medicine, has opened up a space for a shadow-education market providing educational services for those who wish to enhance their chances of obtaining a desired study place.

Courses preparing candidates for the matriculation examination at the end of upper-secondary school, or for the entrance examinations for various higher education institutions, constitute the most visible form of private supplementary tutoring in the Finnish educational field. Preparatory courses are provided by private tutoring companies, and they do not lead to any academic or other official accreditation. Because these courses are not part of the official system the participants are not entitled to study loans or other financial support. The costs are covered by the applicants, and the price range varies from zero to 6,500 euros, the duration of the most expensive ones extending up to nine months (Kosunen et al., 2015).

Earlier studies have shown how these courses have become anchored in several academic disciplines (Kosunen et al., 2015; Räisänen et al., 2015). The previous studies concerning participation on

\footnotetext{
${ }^{1}$ However, fees for students coming from outside EU/EEA countries were introduced in 2016.

${ }^{2}$ Finnish HEIs under the governance of the Ministry of Education and Culture are described as public in this paper, meaning that they do not collect tuition fees (from anyone before 2016), and that they receive about 64 per cent of their funding directly from the government. The concept 'public' could still be criticised given that under the 2010 Universities Act universities have officially become independent corporations under public law, or foundations under private law (Foundations Act). (Ministry of Education and Culture 2016.) However, to make a clear distinction between HEIs that do not collect tuition fees (which were public universities until 2010) and fee-charging, privately owned and governed institutions, the somewhat misleading division between public and private universities is introduced.
} 
preparatory courses have focused on certain fields of study where the supply of the courses has been prominent: medicine, law, business studies and education. According to the findings of Ahola et al. (2017, 2018), within these fields, the participation is more common among applicants coming from higher parental educational backgrounds. Furthermore, the study showed an association between course participation and admittance to the university.

Previously, the most extensive forms of private supplementary tutoring in the Finnish context have been the courses that prepare applicants for university entrance tests. At many other sites, the main focus has for long been on lower levels of education, such as preparation for the examinations at the end of secondary education (Pearce, Power \& Taylor 2017). The university admission system is currently being reformed, with more emphasis on the role of secondary education than has lately been the case. In all probability this will provide a major opportunity to market private tutoring in Finland (see Kosunen \& Haltia, 2018).

Thus, private capital appears to play a role in access to HE in Finland, even if public opinion on admission disapproves of the role of economic capital in this process. The question of private economic capital is connected not only to the possibility of gaining access to some private feecharging institutions locally, but also albeit more discretely to the role of private tutoring in courses given to prepare students for competitive entrance examinations for public and state-funded universities. Our focus in this article is on participation in these courses in terms of who participates in what and how.

\section{The Study}

The key data used in this study comes from a recent national survey on Finnish undergraduate students, conducted in autumn 2016. The Finnish Student Barometer ${ }^{3}$ is a biannual survey covering both the content and social aspects of studying, along with a one-off rotating module that in this round targeted preparatory-course participation and its costs. The general questions in the survey cover topics around admission, proceeding in studies, wellbeing, and future prospective and relation to the labour market after academic studies. Although the survey was aimed at students of universities and universities of applied sciences $(n=5,341)$, this analysis is restricted to the university sub-sample $(n=2,969)$. Participation in preparatory courses is less common among UAS students, and many of those reporting having taken them had chosen a language course rather than a specific disciplinebased preparation course.

\section{The representativeness of the data}

The survey was conducted as a stratified sample among respondents drawn from 14 HEIs (which thus also defines the natural stratification structure of our target population), with an intentional oversampling of smaller regional HEIs. The sub-sample consists of a total of 2,969 university students who completed the online survey. The net response rate was 27 per cent, which is comparable to that of other educational surveys such as the Eurostudent (Hauschildt et al. 2015). In terms of statistical inference, we were able to assess the risk of bias using both internal and external data on studentpopulation characteristics, and made a post-stratification adjustment accordingly.

First, because the sample was drawn from university student registries through the Finnish Ministry of Education Statistics database Vipunen along with contact information and a number of administrative auxiliary variables (gender, age, field of study, duration and type of education) available in the sampling frame, we were able to compare the survey respondents to non-respondents.

\footnotetext{
${ }^{3}$ https://www.otus.fi/hanke/opiskelijabarometri/
} 
For this we used the R-indicator technique that varies from 0 to 1 (the value of 1 indicating complete representativeness) and is based on the variation in estimated response propensities modelled via logistic regression (Schouten et al., 2009). Using register-based data, our sample representativeness yielded an R-indicator value of 0.803 , indicating reasonable representativeness. The estimated response propensities were then incorporated into the sample design weights, the first stage of which accounts for the stratified sampling design.

Second, given that assessment based on external criteria relies upon known population characteristics available through secondary sources, we were able to compare the student SES background which is available by field of study. Using two survey items on parental education we were able to compare the distribution of students with at least one parent holding a HE degree to register-based "gold standard" data from the same year in which our survey was conducted. Comparison of our estimates revealed that the sample seemed slightly over-representative of students with a higher SES background in certain fields of study. We therefore calculated an additional post-stratification adjustment to account for the small field-of-education bias observed in relation to parental education.

\section{Hypotheses and measures}

Our main survey variable of interest was a student self-report item on preparatory-course participation that comprises three categories. The response alternatives were having participated in a preparatory course

a) for their current degree programme,

b) for some other programme and

c) not having participated in any course.

In our sample, 28.8 per cent of university students had taken a preparatory course. 71.2 per cent of those who had participated in one ( $21.5 \%$ of the all respondents) had taken a course that was affiliated with their current study programme at university. This estimated distribution is highly consistent with findings reported in a previous study conducted by the Finnish Ministry of Education and Culture (2014), according to which 22 per cent of university students had taken a preparatory course. However, almost one third of those who had attended a course had ended up being accepted on a programme at the university that did not reflect their initial aim.

The aim of our analysis was to study patterns of participation in these courses. Our main interest was in the kind of university students who had taken preparatory courses in the run-up to the entrance examinations. We address two specific research questions:

1) How are family background and the competitiveness of the study fields connected to participation in private supplementary tutoring?

2) How is economic capital involved in this process?

We set four hypotheses for our empirical analysis. The first one reflects previous research findings indicating that students from higher SES backgrounds are more successful in admission processes, hence: the preparatory-course-participation rate is higher among students from a higher SES background (H1). Parental SES is operationalized as a 3-point index indicating whether one or both of the student's parents had at least a Master's-level degree.

Second, given that participation in preparatory courses demands economic resources, at least in most cases, we hypothesize that students with a higher SES receive more support from their 
parents to finance course participation (H2), and participate in courses that are more expensive (H3). We used survey items concerning the price and financing of the courses to test these hypotheses. The students were asked to report the price of the course they attended using a 16point scale from 1 (less than $100 €)$ to 16 (6000€ or more). The price range was based on the range discovered in an earlier market-study (Kosunen, Haltia \& Jokila 2015). For the purposes of our analysis this item was recoded as a continuous variable (ranging from 100 to 6000 euros) using the midpoints of each interval as well as the lower and upper ends of the scale.

Finally, because admission processes vary between fields which in turn are also variously attractive to students from different socioeconomic backgrounds, we posit following hypotheses: we expect the participation rate to be higher in the fields where the admission is more competitive (H4a), and in the fields where the socio-economic background of the students is higher (H4b). In testing these hypotheses, we enrich our survey data with a measure of field of study by HEI admission competitiveness. As a proxy for the competitiveness of the field, we used the ratio of applicants versus admitted students, which we calculated separately for each field of study and each university. In practice the ratio indicates how many applicants there are per student place. Henceforth, we refer to disciplines with higher ratios as more competitive. It is worth noting that not only do individual fields of study differ in terms of competitiveness, so do individual HEIs. For this measure we conducted a binary logarithmic transformation of the initial ratio for the apparent non-linear (expected) relationship between this predictor and our dependent variable.

The latter hypothesis will be tested using self-reported survey measures, which we also complement with data on the student SES background which is available at the Ministry of Education database Vipunen. This is the same external data which was used as part of the post-stratification weighting adjustment of our respondent background (students of higher SES were found somewhat overly represented among respondents) in assessing the representativeness of our survey data.

To complement the descriptive statistics we applied multivariate analysis to further test the interconnections between course participation, SES background and the competitiveness of the study field, and we used student age, gender and native language as socio-demographic controls in the logistic-regression model. We re-coded student age at the time of the survey to match the age at the time of enrolment, given the potential associations between preparatory-course participation and the student's life-cycle and the time between secondary and tertiary education, as well as having applied multiple times for the current degree programme. In addition, because of the difference in competitiveness not only between study fields but also between HEIs, we constructed the dummy variable Metropolitan HEI, coded 1 if the respondent was enrolled at a HEI located in the Helsinki metropolitan area, and 0 otherwise. Centrally located HEIs tend to be more prestigious than those in rural areas and may thus be more attractive to students with a higher SES background. They may also be more exposed to preparatory-course marketing, since they tend to be concentrated in densely populated urban regions (see Kosunen et al. 2015).

The statistical analyses were carried out by means of Complex Samples (CS) SPSS Logistic regression and Frequencies procedures (version 24), which adjust the standard errors of our estimates to reflect the complex sampling structure (Lee et al., 1986). Second-order Rao-Scott adjustments (Rao $\&$ Scott, 1981; 1984) were used in the cross-tabulations of preparatory-course participation by parental SES assessed according to the field of study.

\section{Socio-economic Differences in Participation in Private supplementary tutoring to Improve the Chances of Accessing Higher Education in Finland}


Our analysis shows a relationship between participation and parental educational background (see Table 1). If neither parent had a HE degree, the preparatory-course participation rate was around 20 per cent, increasing to around 38 per cent if both parents had HE qualifications. Thus, H1 is supported. This finding is in line with results by Ahola et al. (2017, 2018). In the fields they studied, participation was also associated with admittance.

Table 1. Estimated prep-course participation in 2016

\section{Academic parents}

Neither

One

Both

Valid N 2775

\section{Prep-course participants \%}

Design (avg) 1.892
C.I $(95 \%)$

[19.8; 24.9]

[32.2; 43.5]

Effect Effective size 1467

sample

Chi-square $~ 71,5 ; \mathrm{p}<0.01$ (based on the second-order Rao-Scott adjusted F-test)

Most of the students had received parental support for their participation in the preparatory course (Table 2). Some had used their own savings or employment income. Only a few had taken a loan, and in some cases the course was free of charge. Table 2 implies an association between SES and means of financing, showing that students whose parents are highly educated receive more financial help from home. This clearly supports hypothesis $\mathrm{H} 2$.

Table 2. Means of financing prep-course participation by parental education among those who participated

\begin{tabular}{lll}
\hline & \multicolumn{2}{l}{ Parents with HE degree } \\
\cline { 2 - 3 } & Neither & One or both \\
\cline { 2 - 3 } & $\%$ & $\%$ \\
\hline Through savings & $37.9(3.0)$ & $28.7(2.7)$ \\
Loan & $2.5(1.1)$ & $1.5(0.9)$ \\
Employment & $13.5(2.0)$ & $7.6(1.4)$ \\
Financed by parents or other relatives & $58.4(3.2)$ & $77.3(2.5)$ \\
Course was free of charge & $2.1(0.9)$ & $1.1(0.6)$ \\
Other means & $2.7(1.2)$ & $1.3(0.8)$ \\
\hline
\end{tabular}

Valid $\mathrm{N}=841 ;$ Design Effect $=1.90 ;$ Effective sample size $=442$

The third hypothesis (H3) posits that students from a higher-SES background tend to take preparatory courses that are more expensive than the ones other students take. Using the CS General Linear Model 
(CSGLM) procedure of SPSS 25 we conducted a one-way ANCOVA to determine whether parental SES was associated with the price of the preparatory course in question.

The median price range was $€ 500-€ 699(\mathrm{n}=798)$ and there were differences across the disciplines: preparatory courses for medicine (€890 on average) were the most expensive. Controlling for the field of study thus enabled us to assess whether, on average, students from a higher-SES background took pricier courses than their lower-SES peers. We added a second control to account for the fact that the preparatory course in question may have been completely unrelated to the respondent's current degree programme. This was a dichotomous variable derived directly from the survey item.

The predicted main effect of parental SES turned out not to be significant, the estimated price being 55 euros more for higher-SES students (adjusted Wald F $2.27 \mathrm{p}=0.317$; $\mathrm{df}=728$; Deff 1.519). This means that there does not seem to be any variation in the price of preparatory courses taken by applicants from varying backgrounds per se, even if the analysis does not rule out the fact that higher SES students are overrepresented in the fields where these expenses in private supplementary tutoring tend to be higher, into which we will come in H4. We therefore conclude that although preparatorycourse participation seems to be highly selective in terms of SES, it does not seem to follow that there is any significant difference between the price tag of courses within the same chosen field. Noteworthy is also the finding by Ahola et al. (2018) that the price of the course neither the mode of the course (whether it was contact lessons, distance courses or self-study materials) was not related to whether the applicant was admitted.

Finally, as expected, our analysis reveals clear differences between the fields of study in preparatorycourse participation. Table 3 compared fields by combining the numbers on course-participation rates with register-based data concerning the student background as well as average admittance ratios (competitiveness) for different disciplines.

Table 3. Estimated preparatory course participation-rate (survey), parental background of Finnish undergraduate students (Vipunen database) and applicant vs. admitted ratio (Vipunen database 2015- 16)

\begin{tabular}{llll}
\hline $\begin{array}{l}\text { Field of Study } \\
\text { (sample size. unweighted) }\end{array}$ & $\begin{array}{l}\text { Prep-course } \\
\text { participants } \\
\text { (std. error) }\end{array}$ & $\begin{array}{l}\text { Percentage of } \\
\text { parents with } \\
\text { HE degree }\end{array}$ & $\begin{array}{l}\text { Applicant to } \\
\text { admitted ratio }\end{array}$ \\
\hline Medicine (157) & $71.2(4.3)$ & 45.3 & 5.67 \\
Economics. law and administrative studies (415) & $45.5(2.8)$ & 35.9 & 7.53 \\
Educational sciences (285) & $22.0(2.8)$ & 28.5 & 5.10 \\
Agriculture and forestry (73) & $21.0(5.4)$ & 29.0 & 4.51 \\
Social and political sciences (390) & $18.8(2.5)$ & 29.3 & 6.99 \\
Information technology (103) & $12.9(3.1)$ & 29.0 & 3.85 \\
Technical sciences (439) & $11.2(1.5)$ & 36.9 & 3.65
\end{tabular}




\begin{tabular}{llll} 
Health and wellbeing (191) & $5.9(3.7)$ & 18.6 & 1.69 \\
Humanities and the arts (568) & $4.5(0.9)$ & 30.6 & 5.06 \\
Natural sciences (335) & $4.3(1.2)$ & 32.4 & 2.02 \\
\hline $\mathrm{N}$ & 2969 & \\
Effective sample N & 2269 & \\
Design effect (average) & 1.31 & \\
\hline
\end{tabular}

Preparatory-course participation was most common in the field of medicine, where over 70 per cent of the students were estimated to have participated, followed by economics, law and administrative studies ${ }^{4}$ with a little less than 50 per cent. In terms of parental background, the student population in these two fields is the most socially advantaged. Moreover, the applicant-versus-admitted ratios, i.e. the competitiveness of the discipline, are among the highest.

Technical and natural sciences appear to be among the most socio-economically affluent fields, but as Table 3 shows, they are far less competitive and there was a much lower rate of participation in preparatory courses. Educational sciences together with agriculture and forestry as well as social and political sciences constitute a block of study fields in which competition over study places is tough, students come from fairly modest backgrounds, and course participation is quite common. Information technology deviates from this pattern with a lower rate of preparatory-course participation and less competitiveness. The field of health and wellbeing is one in which competitiveness is low as is the SES background of the students, and this seems to generate a low course-participation rate. This is also a field with a different student demography in that the students are older than those in other fields and typically have a professional background in healthcare or nursing (see Rinne, Haltia, Nori \& Jauhiainen, 2008: 77-78).

These observations taken together indicate that competitiveness in the field has a particularly strong link to preparatory-course participation. It also seems that generally high socio-economic profile of the student population increases participation on courses provided that there is enough competition over study places. Thus, among the fields with high socio-economic background together with less competition over study places, we observe lower preparatory course participation rates. However, Humanities and the Arts stands out as an exception. Despite competitiveness and the fact that the students' background is in the middle range, the preparatory-course-participation rate is among the lowest.

The results presented in Tables 1 and 3 the accompanying ANCOVA model indicate that the SESbackground of the student as well as studying in a competitive discipline are associated with the preparatory-course-participation rate independently from one another, supporting hypotheses $\mathrm{H} 1$ and H4a. However, student background comes into play in two respects. First, it may be that applicants with a higher SES-backgrounds may be more likely to take preparatory courses in any case. Second, it may be that the study fields attracting students with a higher SES-background have generated a culture in which taking preparatory courses is more common, even if competitiveness does not explain the high participation rate (see e.g. Kosunen \& Haltia, 2018; Kosunen, Ahtiainen \& Töyrylä,

\footnotetext{
${ }^{4}$ Economics, law and administrative studies are separate fields of study in Finnish universities, but they are combined here in line with the Ministry of Education and Culture's statistics on higher education.
} 
2018). In any case, the competitiveness of the field, SES-background of the students and the participation in preparatory courses are all interconnected in complex ways.

Given that the results are complex, there is a need for more specific analyses of these factors. Complementing the reported estimates, we apply a multivariate model predicting preparatory-course participation in accordance with familial SES-background, field of study and the demographic background characteristics of the admitted students. In order to establish the statistical associations proposed in $\mathrm{H} 1, \mathrm{H} 4 \mathrm{a}$ and $\mathrm{H} 4 \mathrm{~b}$, we controlled for a number of confounding factors that may have biased the results presented in Tables 1 and 3 .

Table 4. Determinants of preparatory course participation among the university sub-sample by student characteristics, SES-background and field of study (CS Logistic Regression)

\begin{tabular}{|c|c|c|c|}
\hline & $\mathrm{B}$ & Std. Error & Odds ratio \\
\hline (Intercept) & -1.261 & $(0.559)$ & 0.283 \\
\hline Gender (=men) & -0.182 & $(0.150)$ & 0.834 \\
\hline Age in years & $-0.088 * *$ & $(\mathbf{0 . 0 1 3 )}$ & 0.915 \\
\hline \multicolumn{4}{|l|}{ Language (other $=$ ref $)$} \\
\hline Finnish & $1.408 * *$ & $(0.394)$ & 4.087 \\
\hline Swedish & $0.643 * *$ & $(0.441)$ & 1.902 \\
\hline Highest parental degree $=$ academic & $0.295 *$ & $(\mathbf{0 . 1 3 1})$ & 1.342 \\
\hline Ratio of applicants to enrolment (binary log) & $0.507 * *$ & (0.101) & 1.661 \\
\hline Location of HEI = capital city region & 0.503 & $(0.169)$ & 1.653 \\
\hline \multicolumn{4}{|l|}{$\begin{array}{l}\text { Field of education } \\
\text { (ref = educational sciences) }\end{array}$} \\
\hline Humanities & $-1.805 * *$ & $(0.294)$ & 0.165 \\
\hline Social Sciences & -0.446 & $(0.260)$ & 0.640 \\
\hline Economics, law, administrative studies & $1.205 * *$ & $(0.222)$ & 3.336 \\
\hline Natural Sciences & $-1.341 * *$ & $(\mathbf{0 . 3 6 9 )}$ & 0.262 \\
\hline Information Science & -0.091 & $(0.399)$ & 0.913 \\
\hline Engineering & $-0.426 * *$ & $(\mathbf{0 . 2 8 5})$ & 0.653 \\
\hline Forestry and agricultural & $-0.415 * *$ & (0.428) & 0.660 \\
\hline Health and wellbeing (excl. medicine) & $-1.800 * *$ & $(0.452)$ & 0.165 \\
\hline Medicine & $1.408 * *$ & $(0.309)$ & 4.088 \\
\hline Valid N & 2953 & & \\
\hline Deff (average) & 1.655 & & \\
\hline
\end{tabular}

Pseudo R Squares

Cox and Snell

0.242

Nagelkerke

0.394

* significant at $<0,05$ level; $* *$ significant at $<0,01$ level.

Table 4 presents the results of a complex samples (CS) logistic regression predicting preparatorycourse participation in accordance with student SES and demographic background, as well as measures of socio-economic profile of the student population and competitiveness in the study fields.

We found a significant association linking both the SES-background and competitiveness with preparatory-course participation even after controlling for the field of study and the location of the 
HEI. As expected, students at HEIs located in the capital-city region also reported higher preparatorycourse-participation rates, although the CS-adjusted estimate did not reach the conventional level of statistical significance. Further findings concerning differences between fields of study also corresponded to our expectations: students in competitive fields such as medicine as well as economics, law and administrative studies were more likely to have taken preparatory courses, whereas their peers in the fields of humanities, health and wellbeing, natural sciences, forestry and agriculture and engineering were among the least likely; students in the fields of education, social sciences and IT were somewhere in the middle. The home language of the student was strongly associated with preparatory-course participation. Those with a Swedish-speaking background (about $5,3 \%$ of the population in Finland) and applying for places on Swedish-language study programmes in universities were less likely to have taken a preparatory course. This could relate to the earlier finding that admission to Swedish-speaking HEIs in Finland is less competitive even though they are socio-economically affluent in terms of the students' SES-background (see Nori, 2011).

There was a negative association between the age of the student and preparatory-course participation, which may be attributable to several coinciding mechanisms of selectivity. First, students starting the same degree programmes at an older age may well have tried their luck in entrance examinations several times, achieving lower success rates than their counterparts taking the preparatory courses. Second, it may be that students entering $\mathrm{HE}$ at an older age are more confident in their skills and abilities to prepare for entrance tests than those who have recently left secondary education. Furthermore, older students may have other duties and responsibilities in life (Rinne et al., 2008), and may well not have as much time as their younger peers to invest in courses.

\section{Conclusion}

We analysed information on the students who participated in preparatory courses and were able and willing to spend money on private supplementary tutoring during the admission process. Our findings indicate clear socio-economic differences in this regard, i.e. as an answer to our research questions, SES-background per se and the competitiveness of the field of study are both associated to the participation in preparatory courses, while this varied across disciplines. We found support for hypotheses H1, H2, H4a and H4b. Preparatory course participants came from higher SES background than non-participants. We also found significant differences between the study fields in the attendance to private supplementary tutoring in regards to the competitiveness of the discipline (H4a). Medicine and the combined field of economics, law and administrative studies stood out as having a large proportion of shadow-education attendees.

Socio-economic background was also associated with how participation in private supplementary tutoring was financed, and thereby answering the second research question, economic capital was involved depending on the socio-economic background of the student as well as the competitiveness of the field. Students from a higher socio-economic background reported parental economic support more often, whereas those with a lower SES were more likely to generate the required finance themselves (H2). This, of course, could be seen as disadvantageous to those who used their time working part-time outside of preparing for their entrance examinations, or were forced to apply for a debt, whereas others were able to put more of their time into the preparation, in many cases over several months. Students from a higher SES-background also participated in courses that where more expensive, but this was largely attributable to the fact that courses in more competitive fields are more expensive in the first place. Thereby our $\mathrm{H} 3$ was not supported per se, even if the connection between economic resources and admission to more competitive disciplines followed by more expensive private tutoring was discovered. 
To conclude, discipline-based participation in preparatory courses was connected to the socioeconomic background of the applicants and the competitiveness of the field, which in turn were interlinked with the origin of money invested in the course. This aspect links our findings with the results of international studies showing how 'investing' money in HE seems to function as a middleclass practice, whereas among the lower socio-economic groups it tends to be perceived as a matter of taking on a debt (see Callender \& Jackson, 2008; also Harrison \& Hatt, 2012). Particularly noteworthy here is the unequal positioning of the applicants, specifically in fields in which the courseparticipation rate among the admitted students was very high. The implication from this analysis is that course participation has become more or less a mainstream path for admission in the most competitive disciplines and is tied to financial resources in complex ways.

The implications of these findings to admission policies are partly controversial. Decisions on where to apply, and whether and what sort of preparatory course to take, are all intertwined, as applicants weigh up the characteristics of the institution and the study field as well as their own attributes and how they 'fit in' to these various options (Reay 2010). As these prospective students match their own performance to the competitiveness of the admission, the question of a preparatory course arises, as does the question of possible voluntary self-exclusion (see Ball et al., 2002; Kosunen \& Haltia, 2018).

In selective processes in education, the effect of social class and mobilizable amounts and forms of different capital are often misrecognized as competence (see Bourdieu, 1986), and the structural inequalities are masked as differences in abilities, interests and motivation (see Kosunen \& Haltia, 2018). This is evident also in the Nordic context, in which the education system is built to diminish the financial constraints of studying (Thomsen et al., 2013). Participation in private supplementary tutoring could be interpreted as a class strategy to secure success in the entrance examination, which as such protects the elitist nature of the most competitive fields of study (see Bourdieu, 1996). Thereby the hidden role of economic capital in reproducing upper- and middle-class positions among the offspring of the higher social classes seems to be fuelled by the existence of private supplementary tutoring. This is a classic example of the transformation of economic capital first into an embodied and then into an institutionalized form of cultural capital (Bourdieu 1984). The influences of SES background and economic resources are evident, even if discretely hidden in the process. These differences are further articulated and legitimized through the meritocratic and thereby presumably 'fair' (see Pitman, 2016; Mountford-Zindars \& Sabbagh, 2013) admission procedure, in which they are transformed into differences in academic success and further on in different positions in the labour market.

\section{Acknowledgements}

This study is a part of Privatisation and Access to Higher Education: a study on power relations, guidance devices and private capital in the transition to higher education-research project and has been funded by Kone Foundation.

\section{References}

Ahola S, Asplund R and Vanhala P (2017) Pääseekö yliopistoon, jos käy valmennuskurssin? [Will you get to university if you take a preparatory course?] Alustavia havaintoja. Tiedepolitiikka 42(2): 58-61.

Ahola S, Asplund R, and Vanhala P (2018) Opiskelijavalinnat ja korkeakouluopintojen nopeuttaminen. Valtioneuvoston selvitys- ja tutkimustoiminnan julkaisusarja 25/2018. 
Archer L, and Hutchings M (2000) 'Bettering Yourself'? Discourses of Risk, Cost and Benefit in Ethnically Diverse, Young Working-Class Non-participants' Constructions of Higher Education. British Journal of Sociology of Education 21(4): 555-574.

Archer L, Ross A, Hutchings M, Leathwood C, Gilchrist R, and Phillips D (2003) Higher education and social class: Issues of exclusion and inclusion. Abingdon: Routledge.

Ball SJ, Davies J, David M, and Reay D (2002) Classification and Judgement: Social Class and the Cognitive Structures of Choice of Higher Education. British Journal of Sociology of Education 23(1): 51-72.

Ball SJ and Youdell D (2008) Hidden privatisation in public education. Brussels: Education International.

Bathmaker AM, Ingram N and Waller R (2013) Higher Education, Social Class and the Mobilisation of Capitals: Recognising and Playing the Game. British Journal of Sociology of Education 34(56), 723-743.

Bourdieu P (1984) Distinction: A Social Critique of the Judgement of Taste. Cambridge, MA: Harvard University Press.

Bourdieu P (1986) The forms of capital. In: Richardsson JG (ed) Handbook of Theory and Research for the Sociology of Education. New York: Greenwood Press, pp. 241-258.

Bourdieu P (1996) The State Nobility: Elite Schools in the Field of Power. Stanford: Stanford University Press.

Bray M (2010) Researching Shadow Education: Methodological Challenges and Directions. Asia Pacific Education Review 11(1): 3-13.

Bray M (2011) The Challenge of Shadow Education: Private Tutoring and Its Implications for Policy Makers in the European Union. Brussels: EC/NESSE.

Callender C (2006) Access to Higher Education in Britain: The Impact of Tuition Fees and Financial Assistance. In Teixeira PN, Johnstone DB, Rosa MJ and Vossensteijn JJ (eds), Cost-Sharing and Accessibility in Higher Education: A Fairer Deal? Dordrecht: Springer, pp. 105-132.

Callender C and Jackson J (2005) Does the Fear of Debt Deter Students from Higher Education? Journal of Social Policy 34(4): 509-540.

Callender C and Jackson J (2008) Does the Fear of Debt Constrain Choice of University and Subject of Study? Studies in Higher Education 33(4): 405-429.

Crawford C, Gregg P, Macmillan L, Vignoles A and Wyness G (2016) Higher education, career opportunities, and intergenerational inequality. Oxford Review of Economic Policy 32(4): pp. 553-575.

Declercq K and Verboven F (2005) Socio-Economic Status and Enrollment in Higher Education: Do Costs Matter? Education Economics 23(5): 532-556.

Forsyth A and Furlong A (2000) Socioeconomic Disadvantage and Access to Higher Education. Bristol: Policy Press.

Hallsén S and Karlsson M (2018) Teacher or friend?-consumer narratives on private supplementary tutoring in Sweden as policy enactment. Journal of Education Policy, 1-16.

Halsey AH (1993) Trends in Access and Equity in Higher Education: Britain in International Perspective. Oxford Review of Education 19(2): 129-140.

Harrison N and Hatt S (2012) Expensive and Failing? The Role of Student Bursaries in Widening Participation and Fair Access in England. Studies in Higher Education 37(6): 695-712.

Hauschildt K, Gwosć C, Nicolai Netz N and Mishra S (2015) Social and Economic Conditions of Student Life in Europe: synopsis of indicators. Eurostudent V; 2012-2015.

Jalava M (2013) The Finnish Model of Higher Education Access. Does Egalitarianism Square with Excellence? In: Meyer HD, St John EP, Chankseliani M and Uribe L (eds), Fairness in Access to Higher Education in a Global Perspective. Reconciling Excellence, Efficiency and Justice, Rotterdam: Sense Publishers, pp. 79-94. 
Kilpi-Jakonen E, Erola J, Karhula A (2016) Inequalities in the haven of equality? Upper secondary education and entry into tertiary education in Finland. In: Blossfeld H-P, Buchholz S, Skopek J and Triventi M (eds) Models of Secondary Education and Social Inequality. Edward Elgar Publishing, pp. 181-196.

Kosunen S (2016) Families and the Social Space of School Choice in Urban Finland. Helsinki: Unigrafia.

Kosunen S and Haltia N (2018) Valmennuskurssit ja koulutuskuluttajuus: tutkimus kurssijärjestäjien puhetavoista [Preparatory courses and educational consumerism]. Sosiologia 55(2): 167-183.

Kosunen S, Haltia N and Jokila S (2015) Valmennuskurssit ja mahdollisuuksien tasa-arvo yliopistokoulutukseen hakeutumisessa. [Prepatory courses and equity in university admission]. The Finnish Journal of Education 46(4): 334-348.

Lee ES, Forthofer RN and Lorimor RJ (1986) Analysis of Complex Sample Survey Data: Problems and Strategies. Sociological Methods \& Research 15: 69-100.

Lynch K (2006) Neo-liberalism and marketisation: The implications for higher education. European Educational Research Journal 5(1): 1-17.

Mangan J, Hughes A, Davies P and Slack K (2010) Fair Access, Achievement and Geography: Explaining the Association between Social Class and Students' Choice of University. Studies in Higher Education 35(3): 335-350.

Marginson S (2016) The Worldwide Trend to High Participation Higher Education: Dynamics of Social Stratification in Inclusive Systems. Higher Education 72(4): 413-434.

Matsuoka, R (2018) Inequality in Shadow Education Participation in an Egalitarian Compulsory Education System. Comparative Education Review 62(4): 565-586.

McCowan, T (2016) Three Dimensions of Equity of Access to Higher Education. Compare: $A$ Journal of Comparative and International Education 46(4): 645-665.

Ministry of Education and Culture (2014) Korkeasti koulutetun väestön kehitys. [Development of of population with higher education degrees]. Opetus- ja kulttuuriministeriön julkaisuja 2014: 12, Aleksi Kalenius. Helsinki: Ministry of Education and Culture.

Ministry of Education and Culture (2016) University Administration and Finance. http://www.minedu.fi/OPM/Koulutus/yliopistokoulutus/hallinto_ohjaus_ja_rahoitus/?lang=en (accessed 14 November 2016).

Mountford-Zimdars A and Sabbagh D (2013) Fair Access to Higher Education: A comparative perspective. Comparative Education Review 57(3): 359-368.

Naidoo R (2004) Fields and Institutional Strategy: Bourdieu on the Relationship between Higher Education, Inequality and Society. British Journal of Sociology of Education 25(4): 457-471.

Nori H (2011) Kenelle yliopiston portit avautuvat? Tutkimus suomalaisiin yliopistoihin ja eri tieteenaloille valikoitumisesta 2000-luvun alussa. [For whom will the university gates open? A study of the selection for admission to Finnish universities and fields of study in the beginning of the 21 st century]. Turku: University of Turku.

Pearce S, Power S and Taylor C (2017) Private Tutoring in Wales: Patterns of Private Investment and public provision. Research Papers in Education. Advance online publication. doi: 10.1080/02671522.2016.1271000

Pitman T (2016) Understanding 'Fairness' in Student Selection: Are There Differences and Does It Make a Difference Anyway? Studies in Higher Education 41(7): 1203-1216.

Rao JNK and Scott AJ (1981) The Analysis of Categorical Data from Complex Sample Surveys: Chisquared Tests for Goodness-of-Fit and Independence in Two-Way Tables. Journal of the American Statistical Association 76: 221-230.

Rao JNK and Scott AJ (1984) On Chi-squared Tests for Multi-way Tables with Cell Proportions Estimated from Survey Data. Annals of Statistics 12: 46-60.

Reay D (1998) 'Always Knowing' and 'Never Being Sure': Familial and Institutional Habituses and Higher Education Choice. Journal of Education Policy 13(4): 519-529. 
Reay D (2003) A Risky Business? Mature Working-Class Women Students and Access to Higher Education. Gender and Education 15(3): 301-317.

Reay D (2010) 'Fitting In' or 'Standing Out': Working-Class Students in UK Higher Education. British Educational Research Journal 36(1): 107-124.

Reay D, Davies J, David M and Ball SJ (2001) Choices of Degree or Degrees of Choice? Class, 'Race' and the Higher Education Choice Process. Sociology 35(4): 855-874.

Rinne R, Haltia N, Nori H and Jauhiainen A (2008) Yliopiston porteilla. Aikuiset ja nuoret hakijat ja sisäänpäässeet 2000-luvun alun Suomessa [At the gate of university. Mature and young applicants and admitted students in the beginning of the 2000s in Finland]. Research in Educational Sciences 36. Turku: Finnish Educational Research Association.

Räisänen M, Kuitunen M, Partanen L and Österlund P (2015) Lääketieteelliseen koulutukseen valikoituminen. [Selection to medical education]. Yliopistopedagogiikka 21(2), 88-92.

Schouten B, Cobben F and Bethlehem J (2009) Indicators for the representativeness of survey response. Survey Methodology 35: 101-113.

Sianou-Kyrgiou E and Tsiplakides I (2011) Similar performance, but different choices: social class and higher education choice in Greece. Studies in Higher Education 36(1): 89-102.

Smyth E (2009) Buying Your Way into College? Private Tuition and the Transition to Higher Education in Ireland. Oxford Review of Education 35(1): 1-22.

Stevenson DL and Baker DP (1992) Shadow Education and Allocation in Formal Schooling: Transition to University in Japan. American Journal of Sociology 97(6): 1639-1657.

Taylor C (2002) Geography of the "New" Education Market. Aldershot: Ashgate.

Thomsen JP (2012) Exploring the Heterogeneity of Class in Higher Education: Social and Cultural Differentiation in Danish University Programmes. British Journal of Sociology of Education 33(4): 565-585.

Thomsen JP, Munk MD, Eiberg M and Hansen GI (2013) The Educational Strategies of Danish University Students from Professional and Working-Class Backgrounds. Comparative Education Review 57(3): 457-480.

Williams J (1997) Negotiating Access to Higher Education: the Discourse of Selectivity and Equity. Buckingham: Open University Press.

van Zanten A (2010) L'ouverture sociale des grandes écoles: diversification des élites ou renouveau des politiques publiques d'éducation? [The social opening of the grandes écoles: diversification of the elites or renewal of public education policies?] Sociétés contemporaines 3: 69-95. 